\title{
Contabilización de ingresos y egresos en la alcaldía La Estanzuela durante el I semestre $2014^{1}$
}

\author{
Karla Patricia Centeno Valdivia ${ }^{2}$ \\ Enma Lissett García Moreno ${ }^{3}$ \\ Cleydi Ramos Lira ${ }^{4}$ \\ Jeyling Maria Alfaro Manzanares ${ }^{5}$
}

\section{RESUMEN}

En el presente trabajo describe el proceso de contabilización de los ingresos y egresos en la alcaldía municipal de La Estanzuela ${ }^{6}$ durante el primer semestre del año 2014, para lo cual se tomó en cuenta lo establecido en las normas técnicas, normas básicas, principios y manual de Contabilidad Gubernamental, con el fin de constatar que la contabilización de ingresos y egresos se estuviese efectuando de forma correcta, además se recomiendan una serie de asientos complementarios a los que dicha alcaldía realiza para que dicha contabilización se realice de forma adecuada. Actualmente la alcaldía de La Estanzuela se encuentra en la categoría " $C$ " con ingresos mayores de seis millones de córdobas y menores a diez millones, los cuales el 30\% conforman el presupuesto municipal. Según el enfoque filosófico es una investigación cualitativa.

Palabras claves: Ingresos, egresos, normas

Recibido: 5 de diciembre de 2014

Aceptado: 20 de junio de 2015

1 Este trabajo fue elaborado a partir de la tesis titulada. Que fue presentada para optar al título de licenciatura en Contaduría Pública y finanzas en el año 2014. UNAN-Managua, FAREM-Estelí.

2 Licenciada en Contaduría Pública y Finanzas. UNAN-Managua, FAREM-Estelí. Correo electrónico:

karlacenteno24@gmail.com

3 Licenciada en Contaduría Pública y finanzas. UNAN-Managua, FAREM-Estelí. Correo electrónico:

lisgae2005@yahoo.com

4 Licenciada en Contaduría Pública y Finanzas. UNAN-Managua, FAREM-Estelí. Correo electrónico:

cleydiramos17@gmail.com

5 M.sc en Contaduría Pública y Finanzas. Tutora de la investigación. Correo electrónico: jeyling2014@gmail.com

6 El nombre de la Alcaldía se cambió por asuntos de sigilo sin embargo toda la información es real. 


\title{
Accounting for income and expenses in La Estanzuela City Hall during the first semester of 2014
}

\begin{abstract}
The present work describes the process of accounting for revenues and expenditures in the municipal government of La Estanzuela in the first semester of 2014, for which it was taken into account the provisions of technical standards, basic standards, principles and manual Government accounting, in order to verify that the accounting for revenues and expenditures was properly performing; also, a number of additional seats is recommended to which the City Hall performs so such accounting is done properly. Currently, the City Hall of La Estanzuela is located in the " $\mathrm{C}$ " category with an income of over six million cordobas and less than ten millions, of which $30 \%$ comprises the municipal budget. According to the philosophical approach it is a qualitative research.
\end{abstract}

Keywords: Income, expenses, standards. 


\section{INTRODUCCIÓN}

El sistema de Contabilidad Gubernamental en Nicaragua se sustenta en la teoría contable, por lo tanto los hechos económicos susceptibles de ser expresados en términos monetarios deben de registrarse sobre la base de los Principios de Contabilidad Generalmente Aceptados en Nicaragua, lo que adaptados del sector público se constituyen en el marco teórico y conceptual de los Principios de Contabilidad Gubernamental de Nicaragua, vinculado con las Normas Básicas de Contabilidad y las Normas Técnicas de Contabilidad Gubernamental, las cuales en conjunto son fundamentos esenciales para sustentar el registro correcto de las operaciones y la elaboración y presentación de estados financieros basados en su razonamiento, eficiencia demostrada, respaldo de legislaciones especializadas y aplicación general de la contaduría gubernamental.

A través de la contabilidad gubernamental los dirigentes a cargo de la conducción del estado deben rendir cuentas a los organismos competentes y al pueblo mismo, para exponer cómo administran el dinero público. Con el afán de conocer e investigar a fondo este tipo de contabilidad se decidió realizar la presente investigación dirigida al trato contable que se le da a los ingresos y egresos en una alcaldía municipal de Nicaragua.

Asimismo hay que tener en cuenta que para el desarrollo del tema seleccionado, se establecieron objetivos que marcan un punto de partida y de llegada que nos enfocan una ruta determinada que va desde describir el proceso de contabilización de los ingresos y egresos durante el I semestre del año 2014, posteriormente comprobarlo con lo establecido en la normativa que regula la contabilidad gubernamental y finalmente evaluar cambios en la presentación de la información financiera en relación a los ingresos y egresos.

Además se detallan registros contables de los ingresos y egresos que realizan en la alcaldía municipal de La Estanzuela, también se revela cuales son los documentos de respaldo que utilizan con el fin de demostrar la legalidad y autorización de las transacciones registradas, de igual forma los libros auxiliares que utilizan y en que normas se basan para el control y registro de todas las operaciones que como entidad pública realizan en relación a los ingresos y egresos.

En los resultados de la presente investigación, específicamente en el primer objetivo se encuentran una serie de operaciones incompletas que realiza la alcaldía identificadas mediante las guía de observación y revisión documental que fueron aplicadas, las cuales en el segundo objetivo se muestra el trato correcto conforme lo establecido en la normativa que regula este tipo de contabilidad, lo cual llevo al cumplimiento del supuesto formulado "La problemática generada en la contabilización de los ingresos y egresos en la alcaldía municipal de La Estanzuela se debe a que no se aplican de forma adecuada la normativa que rigen la contabilidad gubernamental".

\section{MATERIALES Y MÉTODOS}

El estudio es de tipo cualitativo porque se aborda a profundidad el proceso de contabilización de los ingresos y egresos que lleva un ente público. El universo de la investigación está representado por la alcaldía municipal de La Estanzuela y la muestra el área de finanzas de la alcaldía antes mencionada, el tipo de muestreo es no probabilístico, esto significa que no todos los integrantes del universo tienen la probabilidad de ser seleccionados, utilizando el método de muestreo intencional o de conveniencia ya que se trabajó con personal clave en el proceso de contabilización de los ingresos y egresos en la alcaldía municipal de La Estanzuela.

En el desarrollo del estudio se utilizaron fuentes primarias para la recolección de datos como entrevistas semi estructuradas al contador general y 
al responsable financiero, de igual forma se aplicó guías de observación y se realizó revisión documental de toda la papelería que utilizan en el proceso de contabilización, así como el análisis de la información recopilada en la empresa.

\section{RESULTADOS Y DISCUSIÓN}

Los resultados están organizados en cinco aspectos. Primero la referencia teórica de esta investigación; 2) Proceso de contabilización de ingresos y egresos; 3) aplicación de la normativa gubernamental; 4) presentación de estados financieros.

\section{1) Referencia Teórica}

\section{Contabilidad Gubernamental}

Es un medio a través del cual los diversos interesados pueden medir, evaluar y dar seguimiento a la situación financiera de la entidad, por lo tanto su finalidad es proporcionar información útil, confiable y comprensible que sirva de base para tomar decisiones. (Vazquez, 1999)

\section{Ingresos}

El ingreso en el sector público está conformado por los derechos de cobro provenientes, fundamentalmente, de los aportes obligatorios que demanda de las personas naturales y sociedades, haciendo uso de su facultad soberana de coacción; de la venta de los bienes y servicios, lo que obtiene por las concesiones que da al sector privado para que explote sus bienes patrimoniales; lo que percibe por la venta de sus inversiones en bienes de larga duración y el financiamiento que recibe del ahorro interno y externo. (Finanzas)

\section{Egresos}

Los gastos desde la óptica presupuestaria están constituidos por las adquisiciones de "bienes económicos" que realizan las personas o las instituciones para el cumplimiento de sus respectivos objetivos o fines; constituyen las compras de los insumos necesarios para el desarrollo de determinada función productiva, ya sea ésta de índole comercial, industrial, agropecuaria, minera, financiera, profesional, administrativa, etc. (Finanzas)

\section{Estados Financieros}

Los estados financieros son los documentos que debe preparar la empresa al terminar el ejercicio contable, con el fin de conocer la situación financiera y los resultados obtenidos en las actividades de la misma a lo largo de un periodo. (Flores Rugama, 2013).

\section{2) Proceso de Contabilización de Ingresos y Egresos}

\section{- Documentación prenumerada}

Otra deficiencia es que no se utiliza la documentación prenumerada de forma correcta porque se observó que ésta no se encontraba en secuencia numérica según su uso por ejemplo constancias de retención, solicitudes de cheques, recibos de egresos y órdenes de combustible.

\section{- Documentación de respaldo}

Según la revisión documental efectuada encontramos que en la Alcaldía Municipal La Estanzuela en algunos casos hacía falta documentación que respaldara los comprobantes de pago, como facturas en el caso de cancelación o adelantos de proyectos y compras menores (artículos de limpieza, ferreteros y de librería), también les hacía falta firmas autorizadas, recibos de egresos entre otros.

\section{- Archivo de la documentación}

Así mismo la documentación no está archivada de forma adecuada porque no está organizada en orden cronológico, lo que esto dificulta la identificación dl periodo al que corresponde cada transacción. Además que las condiciones físicas del lugar donde ésta se encuentra no cumple con las condiciones óptimas para su resguardo. 


\section{- Contabilización de Ingresos}

Unavezaclaradoloanterior,elprocesodecontabilización de los ingresos tributarios y no tributarios inicia en el momento en donde el contribuyente realiza el pago en caja, el cajero procede a la elaboración del recibo oficial de caja los firma y sella le entrega una copia al cliente, otra contabilidad y una tercera se queda en caja al finalizar el día clasifica los ingresos de acuerdo al catálogo de cuentas del mismo, elabora y envía al área de contabilidad un consolidado, una hoja de arqueo que es recibida por el contador el cual firma y sella junto con el dinero recaudado, posteriormente el contador ingresa esos datos en libro de excel titulado resumen de ingresos diarios; el dinero se acumula y se hace el depósito entre la semana o al finalizar la misma, el depósito se hace a la cuenta corriente a nombre de la alcaldía municipal de la Estanzuela en el Banco de la Producción Sociedad Anónima (BANPRO S.A).

Así mismo el cajero es responsable de registrar y resguardar en un libro auxiliar de caja los impuestos recaudados diariamente.

- Asiento para el registro de ingresos tributarios y no tributarios

\begin{tabular}{llll}
\hline Código & Descripción & Debe & Haber \\
\hline 1111 & Caja General & C\$9,724.00 & \\
11020100 & $\begin{array}{l}\text { Impuestos } \\
\text { sobre ventas }\end{array}$ & C\$500.00 \\
11040200 & IBI Rural & 454.00 \\
12010300 & $\begin{array}{l}\text { Cementerio } \\
\text { Municipal }\end{array}$ & 5000.00 \\
12010500 & $\begin{array}{l}\text { Rastro } \\
\text { Municipal }\end{array}$ & 100.00 \\
12010600 & Corralaje & 80.00 \\
12010700 & $\begin{array}{l}\text { Destace de } \\
\text { Res } \\
12010900\end{array}$ & $\begin{array}{l}\text { Matricula de } \\
\text { Fierro }\end{array}$ & 100.00 \\
12011000 & $\begin{array}{l}\text { Carta de } \\
\text { Venta }\end{array}$ & 440.00 \\
\hline
\end{tabular}
12011100 Guía de
220.00
12011200 Registro
Civil
310.00
13020100 Formularios $\quad 400.00$

Registro de ingresos tributarios y no tributario

C\$ 9,724.00 C\$9,724.00

Fuente: Contabilidad/Alcaldía Municipal de La Estanzuela.

El arqueo de caja es realizado diariamente por el cajero donde se detalla todo lo recaudado durante el día, es realizado con el objetivo de comparar si lo que se encuentra en efectivo es igual a lo registrado en los recibos oficial de caja

El arqueo de caja lo realiza el cajero y se le envía a la contadora para que firme el autorizado.

Resumen de ingresos diarios que realiza el contador

\begin{tabular}{|c|c|c|c|}
\hline \multicolumn{4}{|c|}{ Mes de enero } \\
\hline Código & Descripción & Monto CS & Observaciones \\
\hline 11020100 & $\begin{array}{l}\text { Impuestos } \\
\text { sobre ventas }\end{array}$ & 500.00 & \\
\hline 11040200 & IBI Rural & 454.00 & \\
\hline 12010300 & $\begin{array}{l}\text { Cementerio } \\
\text { Municipal }\end{array}$ & 5000.00 & \\
\hline 12010500 & $\begin{array}{l}\text { Rastro } \\
\text { Municipal }\end{array}$ & 100.00 & \\
\hline 12010600 & Corralaje & 80.00 & \\
\hline 12010700 & $\begin{array}{l}\text { Destace de } \\
\text { Res }\end{array}$ & 100.00 & \\
\hline 12010900 & $\begin{array}{l}\text { Matricula de } \\
\text { Fierro }\end{array}$ & 440.00 & Falta Depósito. \\
\hline 12011000 & $\begin{array}{l}\text { Carta de } \\
\text { Venta }\end{array}$ & 2120.00 & \\
\hline 12011100 & $\begin{array}{l}\text { Guía de } \\
\text { Ganado }\end{array}$ & 220.00 & \\
\hline 12011200 & $\begin{array}{l}\text { Registro } \\
\text { Civil }\end{array}$ & 310.00 & \\
\hline 13020100 & Formularios & 400.00 & \\
\hline $\begin{array}{l}\text { Total del L } \\
\text { Enero }\end{array}$ & Ines 13 de & $9,724.00$ & \\
\hline
\end{tabular}


- Esta es la forma que la alcaldía realiza el registro de depósito a la cuenta de operaciones de ingresos corrientes en el libro de banco.

\section{Contabilización de egresos}

En relación con los egresos específicamente a gastos personales el proceso de contabilización inicia cuando el responsable de recursos humanos elabora la nómina de pago la cual es enviada al contador, posteriormente éste emite un cheque a favor del responsable de recursos humanos por el monto total de la planilla a pagar, con el fin de obtener efectivo para hacer el pago a cada funcionario tomando en consideración la estructura del catálogo de egresos.

Fuente: Contabilidad/ Alcaldía Municipal de La Estanzuela

Los baucher de los depósitos son anexados al archivo de boletería mensual de acuerdo a la fecha de recaudación. En el caso de los ingresos en concepto de donaciones y transferencias el contador lo que hace es registrar los ingresos en un libro de banco por cada una de las fuentes de financiamiento de proyectos por ejemplo: libro de Banco de transferencias del Ministerio de Hacienda y Crédito Público, Fondo de Mantenimiento Vial (FOMAV) y CARE-MARENA-PIMCHAS.

- Registro de transferencia de capital en el libro de banco de Fondo de Mantenimiento Vial.

\begin{tabular}{|c|c|c|c|c|c|c|}
\hline \multicolumn{7}{|c|}{ Libro de Banco de FOMAV } \\
\hline Fecha & $\begin{array}{l}\mathrm{N}^{\circ} \\
\mathrm{Ck}\end{array}$ & Beneficiario & Concepto & Debe & Haber & Saldo \\
\hline $20 / 01 / 14$ & & $\begin{array}{l}\text { Alcaldía } \\
\text { Municipal } \\
\text { de La Estan- } \\
\text { zuela }\end{array}$ & $\begin{array}{l}\text { Transfe- } \\
\text { rencia N } \\
1256556 \\
\text { Proyecto }\end{array}$ & $\begin{array}{l}\mathrm{C} \$ \\
323,568.56\end{array}$ & & $\begin{array}{l}\text { C\$ } \\
323,568.56\end{array}$ \\
\hline
\end{tabular}

Fuente: Contabilidad / Alcaldía Municipal de La Estanzuela

El contador reconoce el pago de planilla como un gasto en el libro diario y después registra el pago en el libro banco de transferencias para gastos corrientes. 


\section{ALCALDIA MUNICIPAL LA ESTANZUELA.}

\section{Comprobante de Diario}

Fecha: 30-01-2014

CD No:

Descripción: Provisión personal.

\begin{tabular}{|c|c|c|c|c|}
\hline Código & Descripción & Parcial & Debe & Haber \\
\hline 1000000 & GASTOS EN PERSONAL & & $\mathrm{C} \$$ & $\mathrm{C} \$$ \\
\hline 1100000 & PERSONAL PERMANENTE & & & \\
\hline 1110000 & RETRIBUCION DEL CARGO & & & \\
\hline 1110300 & Salario Personal & & $85,711.50$ & \\
\hline 1120000 & $\begin{array}{l}\text { RETRIBUCIONES QUE NO HACEN AL } \\
\text { CARGO / ANTIGÜEDAD }\end{array}$ & & & \\
\hline 1120300 & Antigüedad Personal & & $4,560.00$ & \\
\hline 1130000 & $\begin{array}{l}\text { 13ER MES Y OTROS BENEFICIOS / } \\
\text { AGUINALDO }\end{array}$ & & & \\
\hline 1130300 & Aguinaldo Personal Administrativo & & $7,705.00$ & \\
\hline 1140000 & $\begin{array}{l}\text { APORTE PATRONAL PARA JUBILACION / } \\
\text { INSS PATRONAL }\end{array}$ & & & \\
\hline 1140300 & INSS Patronal personal administrativo & & $15,718.20$ & \\
\hline 1400000 & ASISTENCIA SOCIAL AL PERSONAL & & & \\
\hline 1410000 & Contribución patronal al SINACAM & & $1,849.19$ & \\
\hline 1500000 & $\begin{array}{l}\text { BENEFICIOS Y COMPENSACIONES / } \\
\text { INDEMNIZACIÓN LABORAL }\end{array}$ & & & \\
\hline 1530000 & Indemnizaciones & & $7,705.00$ & \\
\hline 2 & PASIVO & & & \\
\hline 212 & SALARIOS POR PAGAR & & & \\
\hline $212-01$ & SALARIOS POR PAGAR & & & $85,711.50$ \\
\hline 212-01-001 & Salarios & & & \\
\hline 213 & PRESTACIONES SOCIALES & & & \\
\hline $213-01$ & PRESTACIONES SOCIALES POR PAGAR & & & \\
\hline 213-01-001 & Antigüedad & & & $4,560.00$ \\
\hline 213-01-002 & Décimo Tercer mes / Aguinaldo & & & $7,705.00$ \\
\hline $213-01-003$ & Indemnización & & & $7,705.00$ \\
\hline 215 & IMPUESTOS ACUMULADOS & & & \\
\hline $215-01$ & IMPUESTOS ACUMULADOS POR PAGAR & & & \\
\hline $215-01-002$ & INSS Patronal & & & $15,718.20$ \\
\hline 215-01-004 & SINACAM & & & $1,849.19$ \\
\hline & TOTAL & & C\$123,248.89 & $\mathrm{C} \$ 123,248.89$ \\
\hline
\end{tabular}

Fuente: Contabilidad / Alcaldía Municipal de La Estanzuela 
- Registro pago de planilla en el libro de banco de transferencia para gastos corrientes y su comprobante de pago (ver anexo $\mathrm{N}^{\circ} 12$ )

\begin{tabular}{|c|c|c|c|c|c|c|}
\hline \multicolumn{7}{|c|}{ Libro de banco de transferencia } \\
\hline Fecha & $\begin{array}{l}\mathrm{N}^{\circ} \\
\mathrm{Ck}\end{array}$ & Beneficiario & Concepto & Debe & Haber & Saldo \\
\hline $30 / 01 / 14$ & 12568 & $\begin{array}{l}\text { Margarita } \\
\text { Castro } \\
\text { Benavides }\end{array}$ & $\begin{array}{l}\text { Pago de } \\
\text { planilla } \\
\text { personal } \\
\text { administrativo } \\
\text { mes de junio. }\end{array}$ & & $\begin{array}{l}\text { C\$ } \\
85,711.50\end{array}$ & $\begin{array}{l}\text { C\$ } \\
950,756.30\end{array}$ \\
\hline
\end{tabular}

Se elabora su comprobante de pago.

Para obtener la cantidad a pagar en concepto de retenciones el contador realiza un resumen de cada uno de los comprobantes del mes a enterar donde suma el total de IR que se retienen de bienes y servicios más el IR de salarios.

Fuente: Contabilidad/Alcaldía Municipal de La Estanzuela

El contador registra esta operación en el libro de banco

Se realiza su correspondiente comprobante de pago al cual se le adjunta una hoja de solicitud de cheque y nómina, que una vez cancelado el funcionario firma de recibido.

- Registro de pago de dietas a concejales en el libro de banco de operaciones de la alcaldía municipal de La Estanzuela y su comprobante de pago.

El cálculo para la dieta de los concejales se realiza en base a los ingresos corrientes del año anterior Cumpliendo con la Ley $\mathrm{N}^{\circ} 828$ Ley de reforma a la ley de régimen presupuestario municipal artículo 18 .

Ejemplo. de operaciones de la alcaldía y en el comprobante de pago.

- Registro de pago de adelantos de proyectos en ejecución

La alcaldía municipal además de las transferencias del Ministerio de Hacienda y Crédito Público recibe financiamiento para la ejecución de proyectos de otros organismos como es el caso de CARE-MARENAPIMCHAS, cuyo objetivo es mejorar la calidad de vida y bienestar de los habitantes del casco urbano y rural de dicho municipio. Como soporte al comprobante de pago en relación a proyecto se adjunta: solicitud de Ingresos corrientes $\mathrm{C} \$ 9,312,000.00$ categorías $\mathrm{C}$, cheque, recibo de egreso, factura o recibo, proforma, número de concejales 14 . cotizaciones de precios y avalúos.

\section{Cálculo}

C\$ 9, 312,000*14\%=1, 303,680.00*30\%= $391,104.00 / 14$ concejales $=27,936 / 12$ meses $=2,328.00(50 \%$ corresponde por cesión ordinaria y $50 \%$ por cesión de comisión de trabajo) Este cálculo corresponde al soporte del cheque para el pago de las dietas. Este ejemplo es el 50\% por cesión ordinaria.

\begin{tabular}{|c|c|c|c|c|c|c|}
\hline \multicolumn{7}{|c|}{ Libro de Banco de CARE-MARENA-PIMCHAS } \\
\hline Fecha & $\begin{array}{l}\mathbf{N}^{\circ} \\
\mathbf{C k}\end{array}$ & Beneficiario & Concepto & Debe & Haber & Saldo \\
\hline $18 / 05 / 14$ & 12552 & $\begin{array}{l}\text { Mauricio } \\
\text { Flores } \\
\text { Castellón }\end{array}$ & $\begin{array}{l}\text { Pago de } \\
\text { adelantos de } \\
\text { proyecto de } \\
\text { agua potable y } \\
\text { alcantarillados } \\
\text { comunidad } \\
\text { Las Maderas. }\end{array}$ & & $\begin{array}{l}\text { C\$ } \\
392,645.63\end{array}$ & $\begin{array}{l}C \$ \\
224,346.68\end{array}$ \\
\hline
\end{tabular}

Fuente: Contabilidad/ Alcaldía Municipal de La Estanzuela

- Registro de pago de dieta en el libro de banco. Se elabora su comprobante de pago.

\begin{tabular}{lllllll}
\hline \multicolumn{7}{c}{ Libro de banco de operaciones } \\
\hline Fecha & $\mathbf{N}^{\circ} \mathbf{C k}$ & Beneficiario & Concepto & Debe & Haber & Saldo \\
\hline $03 / 02 / 14$ & 12535 & Margarita & Pago de dietas & C\$ & C\$ \\
& & Castro & a concejales & $13,566.42$ & $50,569.36$ \\
& & Benavides & mes enero. & & \\
\hline
\end{tabular}

Fuente: Contabilidad/Alcaldía Municipal de La Estanzuela 


\section{3) Aplicación de la normativa gubernamental}

El proceso de contabilización de los ingresos de la alcaldía de La Estanzuela se encuentra incompleto. Según las Normas Básicas de Contabilidad Gubernamental (inciso o) los ingresos se deben registrar en la fecha en que se realizan, lo que permitirá identificarlos con el ejercicio en que efectivamente ocurre su ingreso sea esto en el programa SIAFM o por defecto excel.

Para realizar el registro de los ingresos percibidos la alcaldía municipal de La Estanzuela hace un resumen diario de lo recaudado, pero la forma adecuada de crear el registro según el Manual de Contabilidad Gubernamental en la sección donde hace referencia a la guía de asientos contables "Asientos tipo ingresos" lo correcto es hacer un cargo a banco y un abono a la cuenta por clasificar, posteriormente un segundo asiento donde disminuye ingresos por clasificar y se distribuyen los ingresos según su rubro.

Dado el caso que la alcaldía trabaja con un catálogo de cuentas (ingresos y egresos) actualizado y detallado, algunas cuentas fueron modificadas en la forma y otras omitidas como es el caso de la cuenta en específico ingresos por clasificar, por lo tanto los registros que se muestran a continuación están elaborados en base al catálogo de cuenta que posee la alcaldía misma y tomados en su estructura del manual de contabilidad gubernamental.

Los asientos que se presentan son los que debe de realizar el contador después de recibir el resumen de ingresos diario por parte del cajero, para que el registro de ésta operación quede completo.

En relación a los arqueos de caja las Normas Técnicas de Control Interno donde menciona las normas de caja y banco establecen que los arqueos serán practicados por contabilidad y en caso necesario por la unidad de auditoría interna o por empleados independientes de quienes tienen la responsabilidad de custodia o registros, pero en la alcaldía municipal se incumple esta norma porque el cajero se arquea sólo.

\section{- Documentación prenumerada}

En relación al uso de la documentación prenumerada, las Normas Técnicas de Contabilidad Gubernamental en el párrafo que infiere "Control y uso de la documentación pre numerada" establece que estas formas pre-impresas tales como: recibos de caja, órdenes de compras, facturas, etc., que se utilicen para la sustentación de operaciones financieras serán numerados al momento de su impresión y su uso se controlará permanentemente.

La documentación que se anule por cualquier causa deberá archivarse el juego completo; asimismo aquella documentación que no haya sido utilizada debe ser resguardada por una persona autorizada por un periodo de 10 años.

\section{- Documentación de respaldo}

Las Normas Técnicas de Control Interno en los párrafos concernientes "Documentación de respaldo" y "archivo de la documentación de respaldo" indican que la estructura de control interno y todas las operaciones financieras o administrativas deben tener la suficiente documentación que la respalde y justifique y estar disponible para su verificación y control. La documentación debe ser en original y a nombre de la Entidad u Organismo. Porque estos justifican e identifican la naturaleza, finalidad y resultados de la operación y contienen los datos suficientes para su análisis. 


\section{Comprobante de diario $\mathrm{N}^{\circ} 1$}

Descripción de la transacción: Asiento para registrar la entrada del efectivo a caja en concepto de recaudación.

\begin{tabular}{|c|c|c|c|c|c|}
\hline Código & Fecha & Descripción de la cuenta & Parcial & Debe & Haber \\
\hline 11110000 & $13 / 01 / 14$ & Caja General & & C\$ 9,724.00 & \\
\hline 11111000 & & Caja & $9,724.00$ & & \\
\hline 11010000 & & Matrículas y Licencias & & & C\$ 440.00 \\
\hline 11010400 & & Otras matrículas y licencias (fierros) & 440.00 & & \\
\hline 11020000 & & Impuesto sobre ventas y servicios & & & 500.00 \\
\hline 11021300 & & Por ejercicios por otras actividades & 500.00 & & \\
\hline 11040000 & & Impuesto sobre bienes Inmuebles & & & 454.00 \\
\hline 11040200 & & Rurales & 454.00 & & \\
\hline 12010000 & & Tasas y tarifas & & & $7,930.00$ \\
\hline 12010300 & & Cementerio Municipal & 5000.00 & & \\
\hline 12010500 & & Rastro Municipal & 100.00 & & \\
\hline 12010600 & & Corralaje & 80.00 & & \\
\hline 12010700 & & Destace de Res & 100.00 & & \\
\hline 12011100 & & Carta de Venta & 2120.00 & & \\
\hline 12011200 & & Guía de Ganado & 220.00 & & \\
\hline 12011300 & & Registro Civil & 310.00 & & \\
\hline 13020000 & & Venta de servicios & & & 400.00 \\
\hline \multirow[t]{2}{*}{13020100} & & Venta de Formularios & 400.00 & & \\
\hline & & & & C\$ 9,724.00 & C\$ 9,724.00 \\
\hline
\end{tabular}

Fuente: Manual de contabilidad Gubernamental / Contabilidad Alcaldía de La Estanzuela

Una vez realizada la contabilización de los ingresos, en las primeras horas del día hábil siguiente a su las Normas Técnicas de Control Interno, igualmente recepción. Copia de la minuta de depósito debe pasar establecen en el mismo párrafo de normas de caja y al departamento de contabilidad para su verificación y banco que estos deben ser depositados íntegramente registro posterior.

\section{Comprobante de diario $\mathbf{N}^{\circ} \mathbf{1}^{\mathrm{a}}$}

Descripción de la transacción: Asiento para registrar el ingreso a la cuenta de banco en concepto de recaudación proveniente de caja.

\begin{tabular}{lrlccc}
\hline Código & Fecha & Descripción de la cuenta & Parcial & Debe & Haber \\
\hline 1112 & $13 / 01 / 14$ & Banco & & C\$9,724.00 & \\
11121 & & Fondos Tesorería General de la & $9,724.00$ & & \\
1111 & República & & & C\$9,724.00 \\
1111100 & & Caja General & & \\
\hline & Caja & $9,724.00$ & & $\mathbf{C \$ 9 , 7 2 4 . 0 0}$ \\
\hline
\end{tabular}

Fuente: Manual de contabilidad Gubernamental / Contabilidad Alcaldía de La Estanzuela 
Este segundo asiento es complementario al registro que elabora el contador en el libro de banco de operaciones para que el registro esté completo.

En complemento a las anotaciones que realiza la alcaldía en el libro de transferencia del organismo de Fondo Mantenimiento Vial (por mencionar un ejemplo), se debe de elaborar un comprobante de diario para reconocer la entrada de las transferencias de capital del gobierno central a las cuentas del banco de la alcaldía.

\section{Comprobante de diario $\mathrm{N}^{\circ} 2$}

Descripción de la transacción: Asiento para registrar ingreso en concepto de transferencia de capital del gobierno central.

\begin{tabular}{lclccc}
\hline \multicolumn{1}{c}{ Código } & Fecha & \multicolumn{1}{c}{ Descripción de la cuenta } & Parcial & Debe & Haber \\
\hline 1112 & $20 / 01 / 14$ & BANCOS & & $\mathrm{C} \$ 323,568.56$ & \\
11122 & & Fondos comprometidos Cuenta & $323,568.56$ & & \\
& $\mathrm{~N}^{\circ} 1230567336$ & & \multirow{C}{*}{$\$ 323,568.56$} \\
22010000 & $\begin{array}{l}\text { Transferencias de capital del } \\
\text { gobierno central }\end{array}$ & & & \\
\hline & FOMAV cuenta No1238574690 & $323,568.56$ & & $\mathbf{C \$ 3 2 3 , 5 6 8 . 5 6}$ & $\mathbf{C \$ 3 2 3 , 5 6 8 . 5 6}$
\end{tabular}

Fuente: Manual de contabilidad Gubernamental/Contabilidad Alcaldía de La Estanzuela

\section{Asientos contables de egresos}

En el momento que el contador de la alcaldía municipal de La Estanzuela realice los registros contables de egresos este debe apegarse a lo establecido al Manual de Contabilidad Gubernamental como se muestra a continuación:
Además al realizar los asientos contables se debe considerar que al utilizar una cuenta de mayor se afecte el debe o el haber según el caso y el parcial para las cuentas de detalle esto en cuestión de presentación de los asientos, situación que se presentaba en la alcaldía de La Estanzuela.

\section{Comprobante de diario $\mathrm{N}^{\circ} 3$}

Descripción de la transacción: Asiento para registrar las remuneraciones en el momento del devengado.

\begin{tabular}{|c|c|c|c|c|c|}
\hline Código & Fecha & Descripción de la cuenta & Parcial & Debe & Haber \\
\hline 1110000 & $30 / 01 / 14$ & Retribución del cargo (salarios) & & $\mathrm{C} \$ 92,460.00$ & \\
\hline 1110300 & & Personal administrativo (salarios) & $92,460.00$ & & \\
\hline 1120000 & & $\begin{array}{l}\text { Retribuciones que no hacen al cargo } \\
\text { (antigüedad) }\end{array}$ & & $4,560.00$ & \\
\hline 1120300 & & Personal administrativo antigüedad & $4,560.00$ & & \\
\hline 1130000 & & $\begin{array}{l}\text { Décimo tercer mes y otros beneficios } \\
\text { (aguinaldo) }\end{array}$ & & $7,705.00$ & \\
\hline 1130300 & & Personal administrativo (aguinaldo) & $7,705.00$ & & \\
\hline 1140000 & & $\begin{array}{l}\text { Aporte patronal para jubilación (INNS } \\
\text { Patronal) }\end{array}$ & & $15,718.20$ & \\
\hline 1140300 & & Personal administrativo INSS Patronal & $15,718.20$ & & \\
\hline
\end{tabular}


1400000

1410000

1500000

1510000

2111

21111

21112

211121

211122

211123

21113

211131

211132

2114

21143

2115

21151
Asistencia Social al personal

Contribución patronal al SINACAM

Beneficios y compensaciones/Indemnización Laboral

Indemnizaciones

SALARIOS POR PAGAR

Sueldos por pagar

Prestaciones sociales por pagar

Antigüedad

Décimo tercer mes aguinaldo

Indemnización

Aportes patronales por pagar

INSS Patronal

SINACAM

Retenciones Por Pagar

Retenciones laborales

Prestaciones de la Seguridad Social por pagar

INSS Laboral
$1,849.19$

$1,849.19$

$7,705.00$

$7,705.00$

$\mathrm{C} \$ 85,711.50$

$85,713.50$

$19,970.00$

$4,560.00$

$7,705.00$

$7,705.00$

$17,567.39$

$15,718.20$

$1,849.19$

969.75

969.75

$5,778.75$

$5,778.75$

\section{Total}

C\$129,997.39

C\$129,997.39

\section{Comprobante de diario $\mathrm{N}^{\circ} 4$}

Descripción de la transacción: Asiento para registrar el pago de remuneraciones al personal

\begin{tabular}{|c|c|c|c|c|c|}
\hline Código & Fecha & Descripción de la cuenta & Parcial & Debe & Haber \\
\hline 2120100 & $30 / 01 / 14$ & Salarios por pagar & & $\mathrm{C} \$ 85,711.50$ & \multirow{4}{*}{$\mathrm{C} \$ 85,711.50$} \\
\hline 21201001 & & Sueldos por pagar & $85,810.92$ & & \\
\hline 1112 & & Bancos & & & \\
\hline 11122 & & $\begin{array}{l}\text { Fondos comprometidos Cuenta } \\
\mathrm{N}^{\circ} 1230567336\end{array}$ & 85810.92 & & \\
\hline & & Total & & C\$ 85,711.50 & C\$ 85,711.50 \\
\hline
\end{tabular}

Fuente: Contabilidad / Alcaldía Municipal de La Estanzuela

Asiento para registrar pago de dietas a concejales

\section{Comprobante de diario $\mathrm{N}^{\circ} 5$}

Descripción de la transacción: Asiento para registrar el pago de dietas a concejales

\begin{tabular}{cclccc}
\hline Código & Fecha & \multicolumn{1}{c}{ Descripción de la cuenta } & Parcial & Debe & Haber \\
\hline 1160000 & $03 / 02 / 14$ & $\begin{array}{l}\text { Dietas gastos de representación y honorarios por } \\
\text { comisiones } \\
\text { Dietas }\end{array}$ & $\mathrm{C} \$ 27,330.72$ \\
1160100 & $\quad 27,330.72$ &
\end{tabular}


1112

Banco

$\mathrm{C} \$ 27,330.72$

11121

Fondos tesorería Cuenta de operaciones $\mathrm{N}^{\mathrm{o}}$

1202963454

$27,330.72$

Total

C\$ 27,330.72 C\$ 27,330.72

Fuente: Contabilidad / Alcaldía Municipal de La Estanzuela

Para el registro de pago de adelantos por proyectos se debe de utilizar las cuentas de gastos según catálogo de egresos, aplicar sus correspondientes retenciones, así como revisar que la documentación de respaldo corresponda a los datos presentados en el avalúo.

\section{Comprobante de diario $\mathrm{N}^{\circ} 14$}

Descripción de la transacción: Asiento para registrar el pago en concepto de adelanto de proyecto agua potable y alcantarillado comunidad las Maderas

\begin{tabular}{|c|c|c|c|c|c|}
\hline Código & Fecha & Descripción de la cuenta & Parcial & Debe & Haber \\
\hline 3000000 & $18 / 05 / 14$ & Materiales y suministros & & $\mathrm{C} \$ 376,332.54$ & \\
\hline 3110000 & & Alimentos para personas & $60,000.00$ & & \\
\hline 3240000 & & $\begin{array}{l}\text { Piedra, arcilla, arena y productos } \\
\text { derivados }\end{array}$ & $200,456.45$ & & \\
\hline 3250000 & & $\begin{array}{l}\text { Cemento, cal, yeso y productos } \\
\text { derivados }\end{array}$ & $115,876.09$ & & \\
\hline 3700000 & & Productos metálicos & \multicolumn{3}{|c|}{$28,456.75$} \\
\hline 3750000 & & Herramientas menores & 28456.75 & & \multirow{3}{*}{$C \$ 8,095.78$} \\
\hline 2114 & & Retenciones por pagar & & & \\
\hline 21141 & & Retenciones por impuestos $2 \%$ & $8,095.78$ & & \\
\hline 11020000 & & Impuesto sobre ventas y servicios & & & \multirow[t]{2}{*}{$4,047.89$} \\
\hline 11021200 & & $\begin{array}{l}\text { Por ejercicio de otras actividades } \\
1 \%\end{array}$ & $4,047.89$ & & \\
\hline 1112 & & Banco & & & \multirow[t]{2}{*}{$392,645.63$} \\
\hline 11124 & & $\begin{array}{l}\text { Fondos comprometidos cuenta } \\
\mathrm{N}^{\circ} 1312425432\end{array}$ & $392,645.63$ & & \\
\hline & & Total & & $C \$ 404,789.30$ & C\$ 404,789.30 \\
\hline
\end{tabular}

Fuente: Contabilidad / Alcaldía Municipal de La Estanzuela 
- Registros contables en el libro mayor

La alcaldía La Estanzuela no lleva registros en el libro mayor siendo importante para clasificar las operaciones por cuentas, de tal manera que se pueda conocer el movimiento y saldo de cada una de estas, que servirán de base para la formación de los estados finales, también para comprobar el movimiento de los mayores auxiliares.

La obligación de llevar este libro se contempla en las Normas Básicas de Contabilidad Gubernamental en el inciso i, además no se puede omitir la realización del libro mayor dado a que no solo como una norma técnica para entidades gubernamentales sino también siguiendo con los Principios de Contabilidad Gubernamental Principios de Contabilidad Generalmente Aceptados (PCGA).

\section{4) Presentación de estados financieros}

Las Normas Básicas de Contabilidad Gubernamental, en el inciso r; establece que los entes contables del sector público no financiero deben preparar al cierre del ejercicio los siguientes estados financieros:

1. Ejecución del presupuesto de recursos y gastos

2. Estado de Resultados

3. Estado de origen y aplicación de fondos

4. Balance General

5. Cuentas de ahorro, inversión y financiamiento

Las empresas públicas no financieras prepararan un estado de flujo de efectivo en lugar del estado de origen y aplicación de fondos como es el caso, por lo tanto se elaboró el correspondiente flujo de efectivo con los datos reales que presenta la alcaldía al cierre del I semestre del año 2014.

Se elaboró el estado de flujo de efectivo con los datos reales que presenta la alcaldía, de los demás a excepción del estado de ejecución de presupuestos de recursos y gastos quew si elaboran, se confeccionaron modelos que se pueden utilizar para su elaboración y cumplir con la normativa.

Flujo de Efectivo

Alcaldía Municipal La Estanzuela

Del 01 de enero al 30 de junio

INGRESOS

C\$ 17083,736.39

Saldo del año anterior

C\$ 543,582.31

Ingresos Corrientes

$5529,743.43$

Ingresos Tributarios

4731,214.10

Matrículas y licencias en general

$101,205.18$

Impuesto sobre ventas y servicios

$3681,864.11$

Impuesto de rodamiento

$87,647.46$

Impuesto de bienes inmuebles

$860,497.35$

Ingresos No Tributarios

449,879.19

Tasa por aprovechamiento

$143,829.00$

Tasa por servicios municipales

$275,291.19$

Multas fiscales y otras multas

$30,759.00$

Venta de bienes y servicios

Venta de formularios y otras

impresiones

$348,650.14$

$39,035.00$

Venta de publicaciones

$6,775.00$

Servicio módulo de construcción

$302,840.14$

Ingresos de capital

$11010,410.65$

Transferencias corrientes del

gobierno central

$2121,930.00$

Transferencias de capital del gobierno central

$6790,176.00$

FOMAV

1048,661.92

CARE MARENA PIMCHAS

$1049,642.73$

EGRESOS

$11206,682.95$

Egresos Corrientes

$4155,459.45$

Servicios Personales 
Personal permanente

Horas Extraordinarias

Beneficios y compensaciones

Otros gastos en personal (bono)

\section{Servicios No Personales}

Pagos realizados en servicios

básicos

Mantenimiento de edificios

Alimentos

Papelería impresa

Combustible

Servicios técnicos y

profesionales

Viáticos

Otros servicios personales

\section{Egresos de capital}

Obras públicas en construcción

Imprevistos
$1678,338.93$

$60,554.73$

$32,231.15$

$140,000.00$

2244,334.64

$266,018.41$

$272,888.77$

$166,446.56$

$330,871.87$

$679,223.47$

$129,293.56$

$174,393.00$

$225,199.00$

$\mathbf{7 0 5 1 , 2 2 3 . 5 0}$

$6415,941.77$

$635,281.73$

\section{TOTAL FLUJO DE FECTIVO}

C\$ 5877,053.44

\section{CONCLUSIONES}

La base para el buen funcionamiento de una alcaldía depende no solo de la existencia de normativas que regulen la forma correcta de contabilización sino del adecuado cumplimiento de estas. Teniendo como referencia los datos teóricos y los resultados obtenidos se concluye:

El procedimiento utilizado en la alcaldía municipal de La Estanzuela para la contabilización de los ingresos y egresos se encuentra incompleto, debido a que no utilizan el Sistema Integrado de Administración Financiera Municipal, no se registran en libro diario y mayor las operaciones generadas en el periodo investigado, tampoco se utiliza la documentación

pre numerada de forma adecuada, el archivo de los documentos se encuentra en un espacio reducido y faltan algunos soportes de los comprobantes de pago, siendo estos procedimientos necesarios para la buena contabilización de los ingresos y egresos.

Se analizó cada una de las normativas que rigen la contabilidad gubernamental en relación a los ingresos y egresos, tales como los Principios de Contabilidad Gubernamental, Normas Básicas de Contabilidad Gubernamental y Normas Técnicas de Contabilidad Gubernamental donde se pudo detectar que estas se están incumpliendo debido a que no se contabilizan de forma adecuada, mediante la guía de observación y revisión documental aplicada se comprobó que omiten llevar el libro diario, libro mayor y elaboración de estados financieros, no tienen un control sobre el archivo y la documentación prenumerada.

Se logró elaborar el flujo de efectivo para complementar la información financiera presentada por la alcaldía, además se presenta propuesta del estado de resultados y el balance general, elaborados con el objetivo de reflejar de forma adecuada la situación financiera en que se encuentra actualmente la alcaldía, se pude apreciar que la falta de esta información es negativa para la alcaldía al momento que la Contraloría General de la República u otra firma auditora decidan realizar auditorías.

Por lo antes mencionado se logró comprobar que se cumple el supuesto propuesto "La problemática generada en la contabilización de los ingresos y egresos en la alcaldía municipal de La Estanzuela se debe a que no se aplican de forma adecuada las normativas que rigen la contabilidad gubernamental", debido a que no realizan la contabilización correcta omiten la partida doble, no llevan libro diario, libro mayor, entre otros. Pero que se pueden subsanar esas deficiencias cumpliendo lo establecido en dicha normativa, las cuales están para ser conocidas y aplicadas por todos los funcionarios de las instituciones del Estado por su 
calidad de públicas se deben de practicar con mayor eficiencia.

\section{RECOMENDACIONES}

Según resultados encontrados en el presente trabajo investigativo se pudieron detectar debilidades en cuanto al cumplimiento de la normativa para la contabilización de ingresos y egresos de la alcaldía municipal La Estanzuela, por tal motivo se realizan las siguientes recomendaciones dirigidas al alcalde municipal.

1. Orientar al responsable administrativo financiero la implementación del Sistema Integrado de Administración Financiera Municipal, para el registro de ingresos y egresos esto con el fin de que la alcaldía tenga su contabilidad correctamente ejecutada según la normativa.

2. Solicitar al Instituto Nicaragüense de Fomento Municipal colaboración para el entrenamiento adecuado del personal en el manejo del sistema contable con el propósito de que usen correctamente el Sistema Integrado de Administración Financiera Municipal y puedan emitir los reportes mensuales.

3. Utilizar la documentación pre numerada de forma consecutiva según su uso, para evitar inconsistencias en los mismos.

4. Adecuar un lugar más grande para el archivo de la documentación de manera que esta sea más accesible y fácil de localizar al momento de su uso.

5. El contador deberá de solicitar al responsable de proyectos los documentos soportes que avalen los gatos referentes a proyectos en ejecución.

\section{BIBLIOGRAFIA}

Finanzas, M. d. (s.f.). Manual de contabilidad Gubernamental. En M. d. finanzas.

Flores Rugama, J. (2013). Contabilidad y finanzas Gubernamental.

En R. C. Vazquez, (1999) .Contabilidad Gubernamental (pág. 147). México: Instituto Mexicano de Contadores Públicos. 